\title{
A ACESSIBILIDADE NO PROCESSO DE INCLUSÃO NAS ESCOLAS PÚBLICAS DE FORTALEZA
}

\author{
BELISARIO, Thaynara Mayra Maciel (1); \\ WAGNER, Milena Scur (2); \\ ALVES, Ana Caroline Dias (3); \\ ANGELIM, Patrícia Barreira (4) \\ SANTIAGO, Zilsa Maria Pinto (5)
}

(1) Universidade Federal do Ceará, Graduanda e-mail: thaynarabelisario@arquitetura.ufc.br

(2) Universidade Federal do Ceará, Graduada e-mail: milenascur@gmail.com

(3) Universidade Federal do Ceará, Graduanda e-mail: carolinealves@arquitetura.ufc.br

(4) Universidade Federal do Ceará, Graduanda e-mail: patrícia@angelim.com.br

(5) Universidade Federal do Ceará, Doutora e-mail: zilsa@arquitetura.ufc.br

\begin{abstract}
RESUMO
O ambiente escolar possui importância indiscutível no processo de formação de qualquer pessoa, devendo garantir pleno acesso a todos que compõem esse espaço. O presente trabalho tem como objetivo estudar e analisar as condições de acessibilidade física em escolas públicas de diversos bairros da cidade de Fortaleza, contribuindo com a construção de um panorama geral no que diz respeito à acessibilidade espacial dos prédios escolares já construídos e buscando reforçar a importância do desenho universal na arquitetura escolar. Apresenta resultados de pesquisa sobre acessibilidade nos prédios escolares das seis regionais de Fortaleza, tendo como referência metodológica técnicas da Avaliação Pós-Ocupação.
\end{abstract}

Palavras chave: Acessibilidade; Escolas Públicas; Avaliação Pós-Ocupação.

\begin{abstract}
The school environment has undoubted importance in the process of training of any person, and must guarantee full access to all that make up this space. The present work aims to study and analyze the physical accessibility conditions in public schools of various neighborhoods of the city of Fortaleza, contributing with the construction of a general panorama regarding the space accessibility of school buildings already built and seeking to reinforce the importance of universal design in school architecture. Presents results of research on accessibility in the school buildings of the six regional schools in Fortaleza, using the technical methodology of Post-Occupancy Evaluation (POE).
\end{abstract}

Keywords: Acessibility; Public Schools; Post-Occupancy Evaluation. 


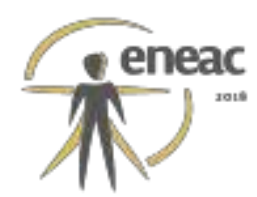

\section{INTRODUÇÃO}

O termo acessibilidade engloba diferentes aspectos, dentre eles a acessibilidade física que se refere aos diversos ambientes que compõem 0 ambiente construído e suas particularidades.

Pela importância inerente da acessibilidade, como forma de possibilidade e condição ampla de acesso e uso dos ambientes e objetos, essa preocupação deve estar presente no momento de concepção de projeto dos edifícios escolares, visto que esse é um espaço que deve garantir o acesso completo a toda e qualquer pessoa, sejam estes alunos, funcionários, pais ou mesmo visitantes. A acessibilidade, portanto, não deve ser vista como secundária nesse processo, e precisa ser compreendida e difundida entre os projetistas, arquitetos e instituições públicas e privadas detentores das decisões de projetos.

No que se refere à legislação, a promulgação do Decreto Federal n5.296, em 2004, propiciou maior atenção às necessidades das pessoas com deficiência e com mobilidade reduzida. Além disso, a revisão da NBR 9.050 em 2015 e a criação da NBR 16.537 em 2016 permitiram definir importantes parâmetros e representaram importante avanço nesse campo. Assim, são os elementos norteadores dos relatórios técnicos produzidos nesse projeto.

O presente trabalho faz parte do projeto de extensão "Acessibilidade nas Escolas de Ensino Fundamental e Médio das redes públicas, estadual e municipal", desenvolvido pelo Departamento de Arquitetura e Urbanismo na Universidade Federal do Ceará (UFC) em parceria com o Ministério Público do Estado do Ceará (MPCE). Possui como objetivos elaborar relatórios técnicos acerca de cada visita realizada nos seis distritos de Fortaleza a fim de verificar a adequação de cada escola quanto às normas e decretos referentes à acessibilidade, além de fomentar o debate sobre a importância de se pensar acerca da acessibilidade ainda na fase de projeto das edificações escolares, por parte dos arquitetos e instituições responsáveis.

\section{METODOLOGIA}

Utilizou-se como metodologia de pesquisa de campo, a Avaliação Pós-Ocupação (ORNSTEIN, 1992), que é o processo de coleta de dados, análise e comparação com critérios de performance explicitamente declarados, de ambientes construídos e ocupados (PREISER, 1998). Essa metodologia busca identificar aspectos negativos e positivos da edificação, e elaborar sugestões que possam contribuir para minimizar ou solucionar os problemas existentes.

Portanto, a partir de visitas realizadas às escolas, todo o ambiente escolar é analisado quanto a sua adequação ou não às normas vigentes. Para isso, fez-se o levantamento arquitetônico dos ambientes gerais, tais como salas de aula, refeitório, banheiros e ambientes administrativos, como também dos ambientes que vão além da sala de aula, como bibliotecas, laboratórios de informática, auditórios, quadras esportivas e playgrounds.

Os critérios avaliados variam conforme cada ambiente, e abrangem características como: comunicação visual, comunicação em Braille, dimensão de vão das portas de acesso aos ambientes, tipos de maçaneta, presença de desnível no acesso, presença e adequação de rampas, condições de piso, contraste de cor entre piso e parede, altura de quadro (lousa), altura de mesas, bancos e cadeiras, alturas de lavatórios, tipos de maçanetas, e presença e adequação de barras de apoio em banheiros.

Após as visitas realizadas, foram elaborados relatórios técnicos contendo o diagnóstico de cada ambiente, por meio de registro fotográfico e apontamentos referentes às condições 


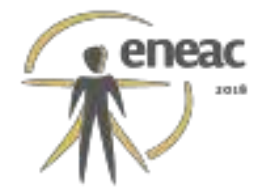

atuais e intervenções necessárias ao cumprimento da legislação vigente e principalmente à possibilidade de acesso para todas as pessoas que compõem o ambiente escolar.

\section{ANÁLISE E RESULTADOS}

As visitas a cada escola seguiram a mesma metodologia já citada, e a seguir foram apresentados alguns resultados dessa pesquisa que ainda está em andamento. Apesar de ainda não ter sido concluída, apenas no segundo semestre de 2017 e início de 2018, mais de vinte e cinco escolas foram visitadas e os dados obtidos já expressam bastante como se encontra a situação geral das escolas públicas de Fortaleza. Os resultados estão divididos pelos setores e apontam as questões mais pertinentes em cada ambiente e que se mostram constantes nas escolas visitadas.

\subsection{Acessos e Travessias}

Nesse aspecto, o acesso imediato à escola é analisado, observando se há faixa de travessia de pedestres, e havendo, se a mesma está de acordo com a norma, e se há sinalização adequada.

Em muitas das escolas visitadas, não há a presença de faixas de pedestres para realização do acesso seguro (Figuras 1 e 2). Percebe-se ainda outro problema recorrente, que é a utilização de piso inadequado de acordo com a NBR 9050/2015, que indica a utilização de revestimento que garanta uma superfície regular, firme, estável e não trepidante (Figuras 1, 2 e 4). Nestas três escolas apresentadas, fez-se uso da pedra portuguesa na calçada, e este material além de ser trepidante, parte dele pode se desprender quando não assentado adequadamente.

Em outros casos, há a correta utilização da faixa de travessia de pedestres (Figura 3). Nesse caso, há uma faixa elevada, que está de acordo com a NBR 9050/2015, que estabelece ainda outros dois tipos: redução de percurso ou rebaixamento da calçada.

Há ainda muitos casos em que a faixa está presente, mas não obedece ao indicado nas normas (Figura 4). Nesse caso, o rebaixamento da calçada está dentro do percentual estabelecido de $8,33 \%$ de inclinação, porém não possui as abas laterais na rampa e ainda há um poste criando uma barreira física.

Figura 1 - Acesso à escola.

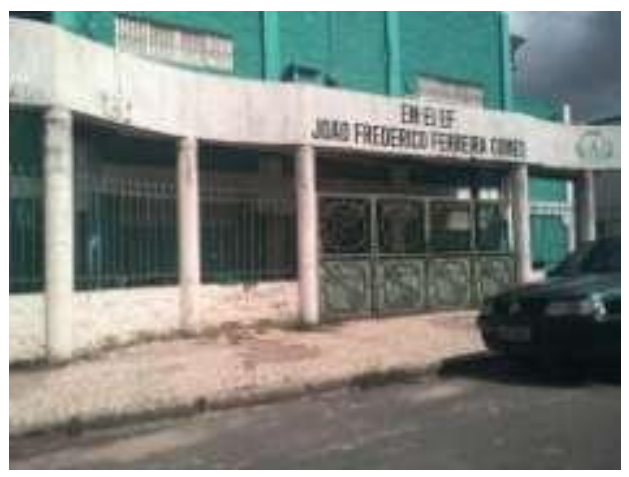

Fonte: Acervo da Pesquisa (2017).
Figura 2 - Acesso à escola.

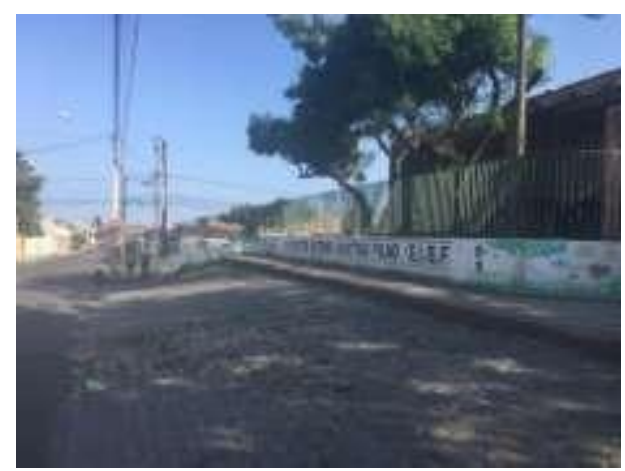

Fonte: Acervo da Pesquisa (2017). 


\section{remes $^{2}$}

Figura 3 - Acesso à escola.

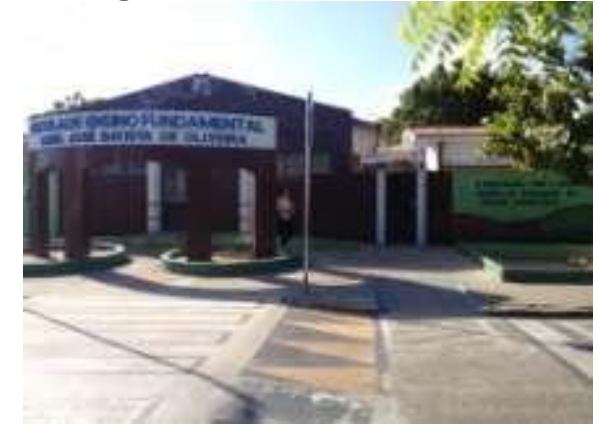

Fonte: Acervo da Pesquisa (2017).
Figura 4 - Acesso à escola.

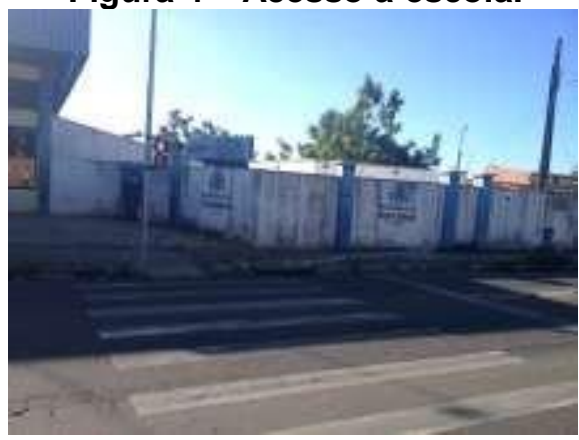

Fonte: Acervo da Pesquisa (2018).

\section{2. Área de Convivência e Pátios}

Os relatórios técnicos elaborados apontam um problema recorrente nas escolas quanto aos desníveis a serem vencidos. Em muitos casos, rampas são construídas sem embasamento técnico, utilizando-se o recurso financeiro, que já é escasso, para a construção de algo que não atende ou atende de modo ineficaz às pessoas em cadeiras de rodas ou com dificuldade de locomoção (Figura 5). Em outros casos, não há rampas e o desnível é vencido apenas com degraus, o que acontece principalmente no acesso aos pátios descobertos (Figura 6) e aos playgrounds (Figura 7a).

Figura 5 - Rampas presentes em áreas de convivência e pátios.
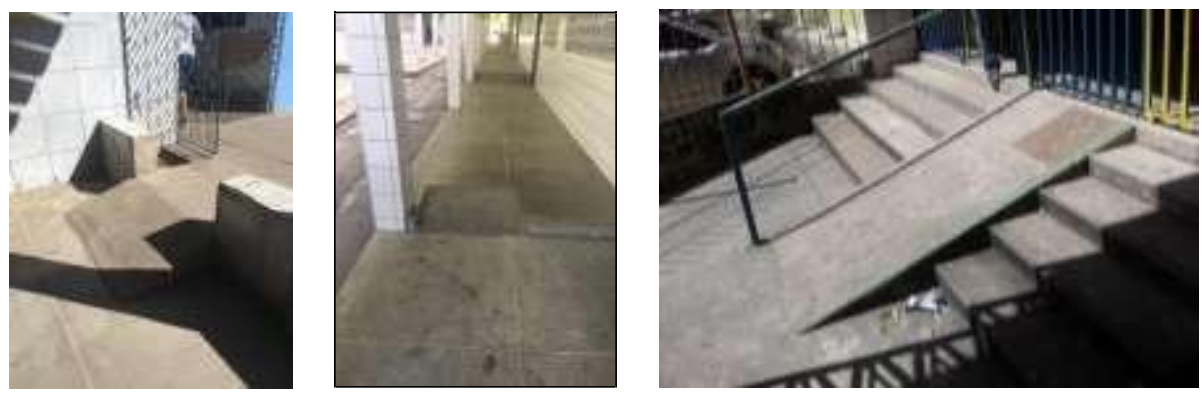

Fonte: Acervo da Pesquisa (2017).

Os pisos utilizados nos pátios cobertos costumam ser adequados, regulares e não trepidantes (vide Figura 8), porém nos pátios descobertos e playgrounds normalmente é usado piso trepidante, mal nivelado (vide Figura 6) ou areia (vide Figura 7a), que estão em desacordo com a NBR 9050/2015. É recomendado que, se possível, pavimentar toda ou parte da área (Figura 7b).

Nos pátios cobertos, em alguns casos, há a presença de um pequeno palco usado em eventos escolares. $O$ acesso a esse palco se dá normalmente por escada e quando há presença de rampa, esta possui inclinação maior do que a recomendada pela norma, que seria menor ou igual a 8,33\% (Figura 8).

Ainda nas áreas de convivência, encontram-se os bebedouros, que normalmente estão em desacordo com a norma de acessibilidade. A NBR 9050/2015 recomenda instalar bebedouros com no mínimo duas alturas diferentes de bicas (uma a 0,90 m e outra entre $1,00 \mathrm{~m}$ e 1,10 $\mathrm{m}$ do piso). Além disso, o bebedouro deve possuir uma altura livre inferior de $0,73 \mathrm{~cm}$ quando possuir bica de $0,90 \mathrm{~cm}$ e garantir aproximação frontal para pessoas em cadeira de rodas. Há casos em que, por não possuir altura adequada de bica, coloca-se o bebedouro móvel em cima de um degrau (Figura 9a). Porém, isso impede a aproximação de uma cadeira de rodas. No que diz respeito aos bebedouros fixos, muitas vezes estes 


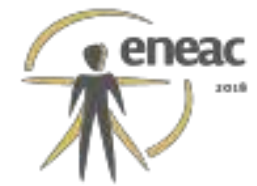

possuem as duas alturas de bica, mas normalmente não estão de acordo com o que é recomendado.

Figura 6 - Pátio descoberto

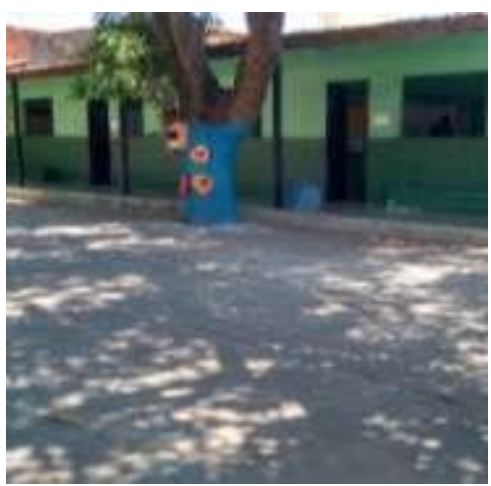

Fonte: Acervo da Pesquisa (2017)
Figura 7 - Playground sem pavimentação

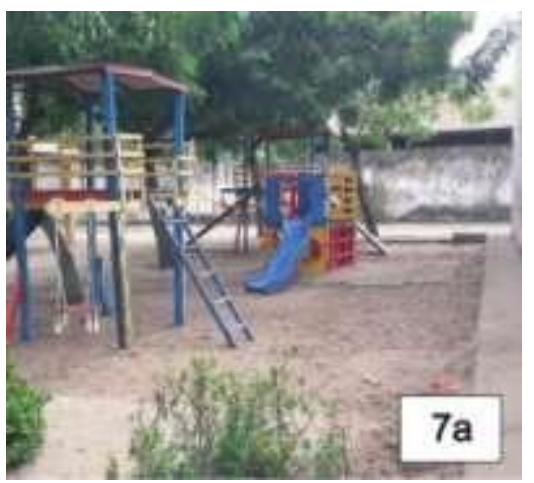

Figura 8 - Playground pavimentado

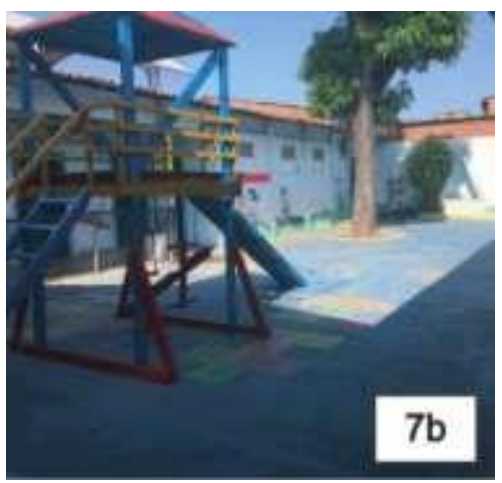

Fonte: Acervo da Pesquisa (2017).

Figura 8 - Pátio coberto.

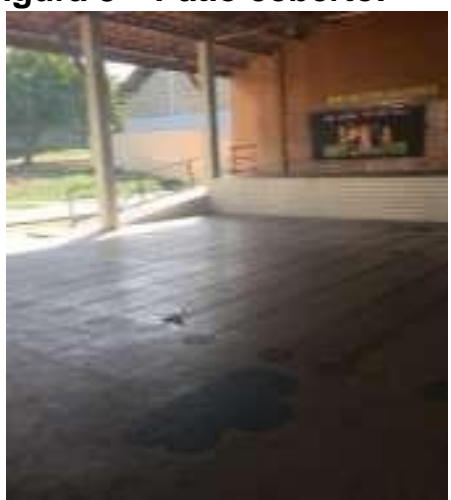

Fonte: Acervo da Pesquisa (2017)
Figura $9 a$ e $9 b$ - Bebedouros
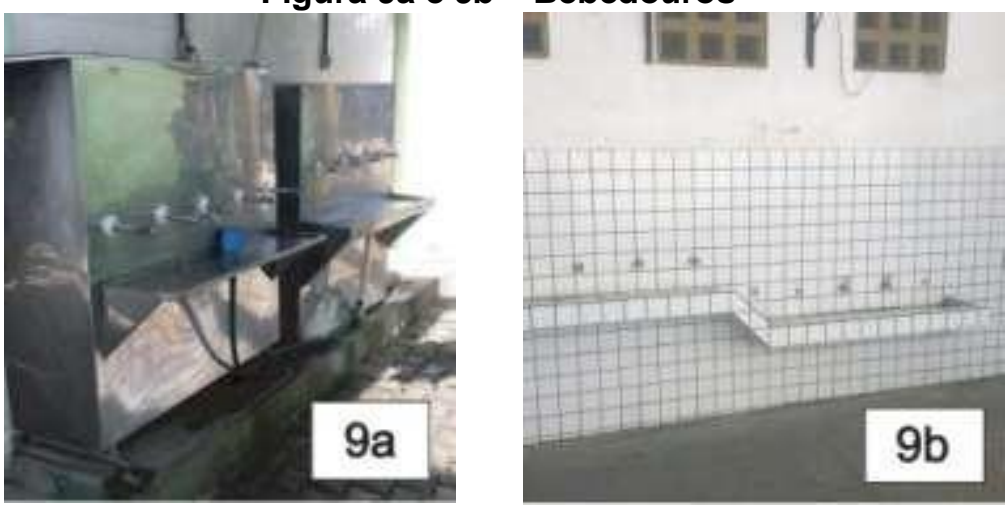

Fonte: Acervo da Pesquisa (2017).

\section{3. Área Administrativa}

A acessibilidade na área administrativa deve se iniciar já no balcão de atendimento da secretaria/diretoria, que segundo a NBR 9050/2015, deve possuir altura máxima de $90 \mathrm{~cm}$ e área de aproximação de, no mínimo, $30 \mathrm{~cm}$. Na maioria das escolas, esse balcão, quando existente, encontra-se em alturas mais elevadas e com área de aproximação inferior à mínima recomendada (vide Figura 10, em que a altura mais de $1 \mathrm{~m}$ e área de aproximação é de apenas $20 \mathrm{~cm}$ ). Há casos em que não há balcão de atendimento (Figura 11).

Em muitas escolas, os ambientes administrativos possuem um desnível de acesso e algumas rampas são feitas no intuito de permitir a acessibilidade, o que representa certa preocupação. Entretanto, novamente, essas rampas são executadas sem auxílio técnico quanto às normas de acessibilidade, e não são adequadas, possuindo inclinação superior à recomendada e sem piso de alerta (Figura 10). Além disso, é importante assegurar que a porta de acesso possui vão livre mínimo de $0,80 \mathrm{~m}$, pois com vãos menores dificulta o acesso por usuários de cadeira de rodas (Figura 13). 


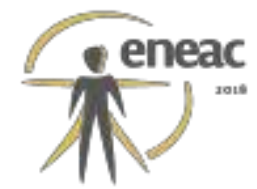

Em muitos casos, faz-se uso de maçaneta tipo bola (Figura 12), enquanto a recomendada pela norma é a maçaneta tipo alavanca, que permite uma pega fácil e firme, garantindo autonomia (Figura 13); ou não raramente, a maçaneta está quebrada (Figura 12).

Há também uma preocupação quanto à comunicação visual, visto que o recomendado em norma é uma altura entre $1,40 \mathrm{~m}$ e $1,60 \mathrm{~m}$ e com indicação em Braille ou em relevo instalada a altura que varie entre $0,90 \mathrm{~m}$ e $1,10 \mathrm{~m}$. Em nenhuma escola visitada há essa indicação em Braille ou relevo e a comunicação visual comumente possui uma altura maior que a recomendada (Figuras 10,11, 12 e 13). Isso dificulta a visualização por uma pessoa em cadeira de rodas e até mesmo pelas crianças de forma geral, visto que está fora da linha de visão.

Figura 10: Balcão da diretoria

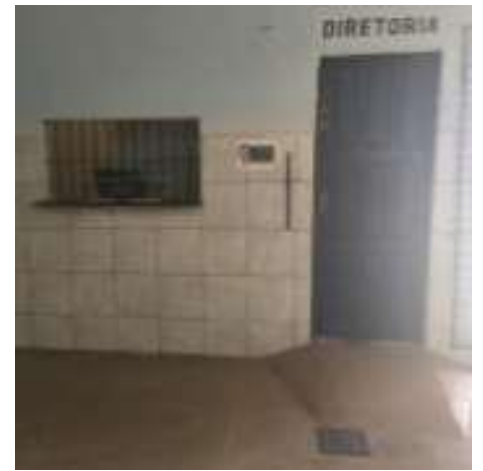

Fonte: Acervo da Pesquisa (2017)
Figura 11: Secretaria Figura 12: Salas administrativas
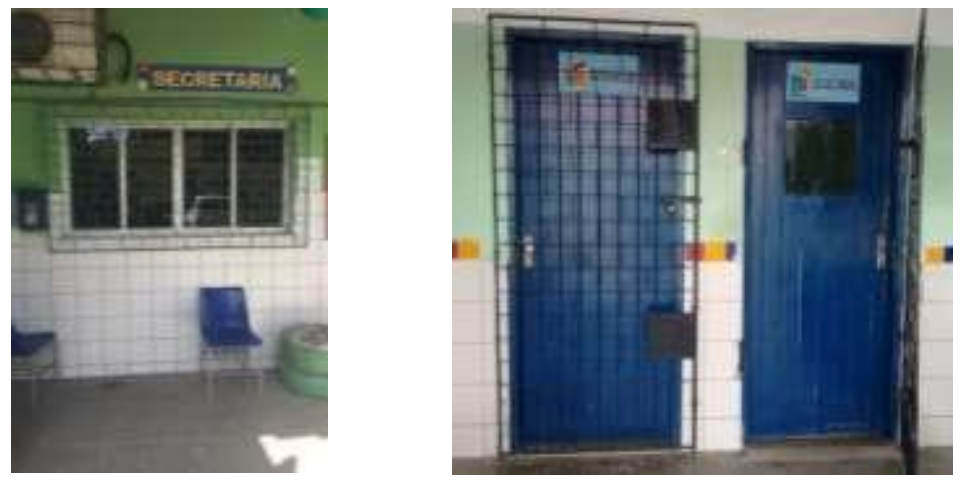

Fonte: Acervo da Pesquisa (2017).

Outra importante questão é o uso de um sistema de mola para fechamento automática de portas (Figura 14a). Algumas salas de secretaria e/ou diretoria se utilizam desse recurso, o que acaba por dificultar a acessibilidade, visto que essa mola força a porta a fechar exigindo maior força ao abri-la. Portanto, o uso desse equipamento não é recomendado no que diz respeito à acessibilidade.

Um problema recorrente é o estrangulamento das passagens e espaço dentro dos ambientes administrativos (Figura 14b), e isso ocorre devido ao grande número de mobiliário dentro de um espaço muitas vezes pequeno. Apesar de acontecer com freqüência, isso pode ser facilmente resolvido apenas alterando o layout do ambiente ou reduzindo a quantidade de móveis, muitas vezes não necessitando de reforma. É preciso garantir não apenas o acesso, como também o fluxo dentro do ambiente, com passagens de larguras adequadas (Figura 14c).

Figura 13 - Diretoria

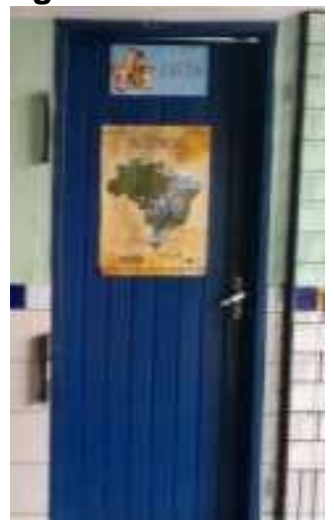

Fonte: Acervo da Pesquisa (2017)
Figura 14a, 14b e 14c-Salas administrativas.
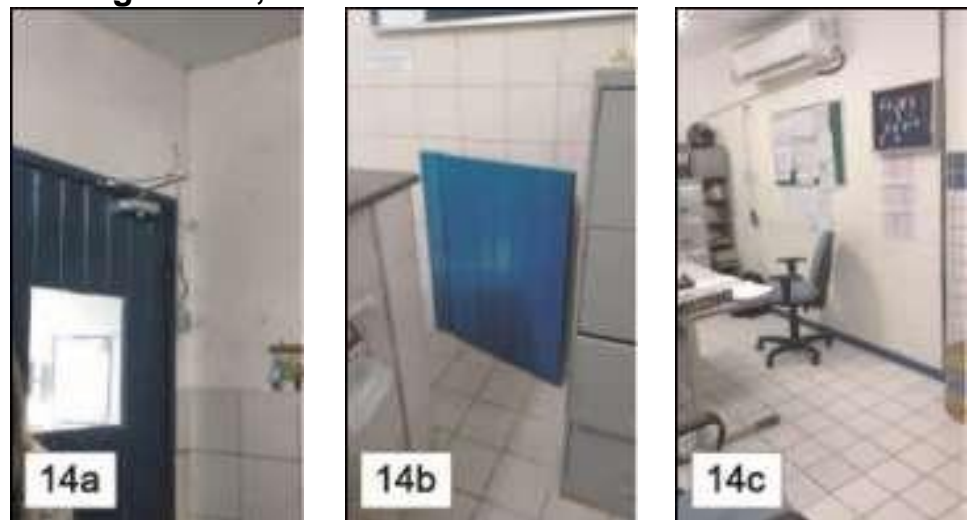

Fonte: Acervo da Pesquisa (2017). 


\subsection{Refeitório}

No que diz respeito ao ambiente de refeitório, algumas escolas não apresentam este ambiente bem definido, ou, de outra forma, possuem mesas com altura adequada, porém muitas vezes com bancos fixos que impedem a aproximação da cadeira de rodas (Figura 15a). Isso pode ser resolvido optando por deixar um dos lados livre de bancos fixos, o que permite a entrada da cadeira de rodas (Figura 15b). Por ser um ambiente que precisa ser lavado constantemente, a escola muitas vezes opta por revestir piso e paredes com a mesma cerâmica ou da mesma cor, e isso impede o contraste visual, o que dificulta a percepção de término do chão e início da parede por pessoas com baixa visão (Figuras 15a, $15 b$ e 16).

Em alguns casos, o balcão para receber refeições possui altura superior à recomendada e algumas vezes sem área de aproximação (Figura 16). A NBR 9050/2015 recomenda uma altura máxima de $80 \mathrm{~cm}$ e aproximação de, no mínimo, $30 \mathrm{~cm}$, lembrando que a distribuição dos alimentos, como sopa, é impossível para crianças menores neste balcão.

Figura 15a e 15b - Refeitório.
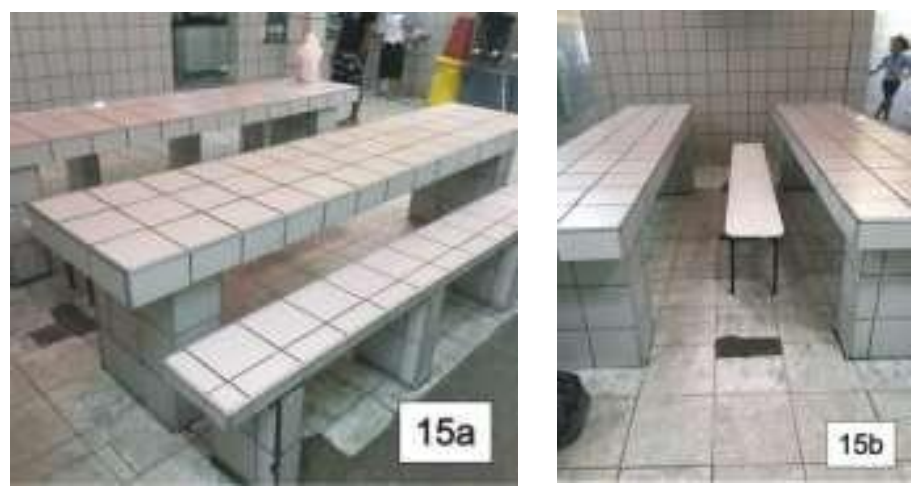

Fonte: Acervo da Pesquisa (2017).
Figura 16 - Balcão do refeitório.

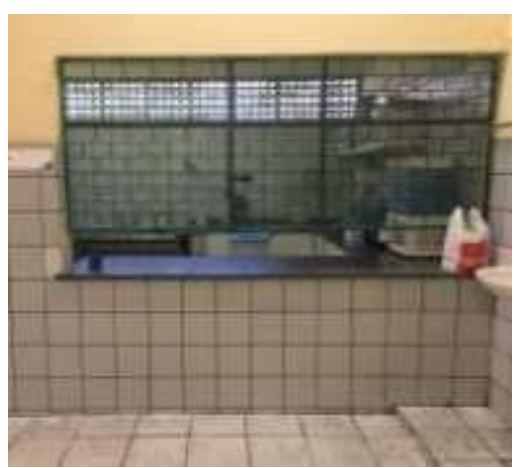

Fonte: Acervo da Pesquisa (2017).

\subsection{Biblioteca, Laboratório de Informática, Auditório e Sala Multiuso}

Em muitas escolas, a biblioteca e o laboratório de informática, por questões de segurança, se localizam no $2^{\circ}$ pavimento e comumente o acesso é feito por escadas; quando há uma rampa de acesso, em sua maioria, esta possui inclinação acima da recomendação da norma, que é de no máximo 8,33\%. Das escolas visitadas, apenas duas possuem elevador, e somente em uma delas estava funcionando.

Comumente, esses ambientes também apresentam desnível no seu acesso, estando em desacordo com a NBR 9050/2015. É preciso garantir ainda um vão livre de no mínimo 0,80 $\mathrm{m}$. Nestes ambientes é comum o uso da maçaneta do tipo bola, devendo ser trocada para maçaneta do tipo alavanca (Figura 17).

A mesma preocupação quando à comunicação visual citada nos ambientes administrativos, acontece nos ambientes em questão, em que em nenhuma das escolas visitadas há indicação em Braille ou relevo e a comunicação visual comumente possui uma altura maior que a recomendada (Figura 17).

Quanto à biblioteca, os espaços destinados a esse uso se mostram suficientes em área, mas com um layout que impede um acesso amplo. Apenas uma realocação das mesas e estantes pode ser suficiente para garantir o livre acesso às pessoas com deficiência. Porém, em alguns casos, as mesas não possuem altura livre inferior adequada para o acesso a cadeira de rodas, que de acordo com a NBR 9050/2015 deve ser de 0,73 m e largura de $0,80 \mathrm{~m}$. O mesmo cenário é comum também nos laboratórios de informática (Figura 19). 
Figura 17:

Informática

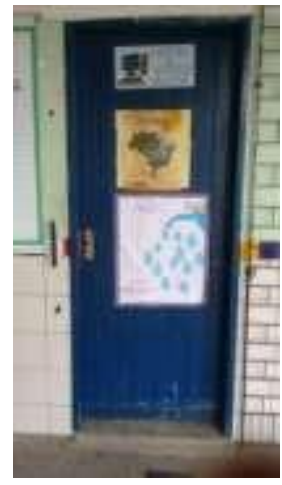

Figura 18: Biblioteca.

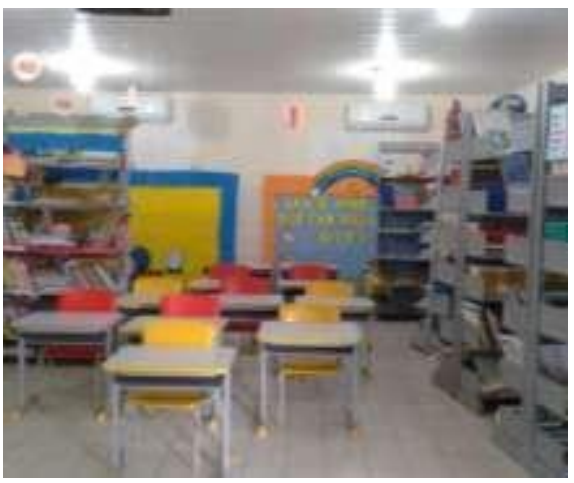

Figura 19: Laboratório de informática.

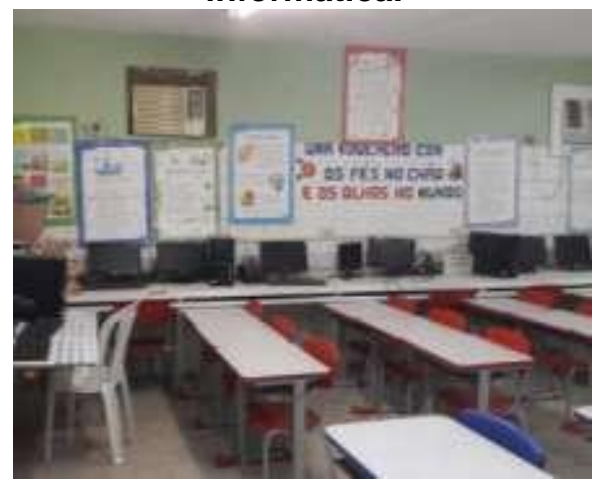

Fonte Figuras 17, 18 e 19: Acervo da Pesquisa (2017).

Verificou-se que o auditório é um espaço pouco comum nas escolas públicas visitadas. No caso de um dos auditórios que está funcionando, a porta de acesso possui vão maior do que o recomendado, porém é um portão muito pesado e sem maçaneta, o que dificulta a autonomia de pessoas com deficiência; além disso, a comunicação visual está acima da recomendada (Figura 20a). Em seu interior, há rampas em ambas as laterais da platéia, com inclinação adequada, que permitem o acesso por pessoas com deficiência (Figura 20b). O espaço entre o palco e platéia possui ótima largura, permitindo que exista livre acesso no ambiente (Figura 20c). Já no palco, o acesso é feito somente por degraus, o que impede o livre acesso por pessoas em cadeira de rodas (Figura 20d).

Figura 20: Auditório.
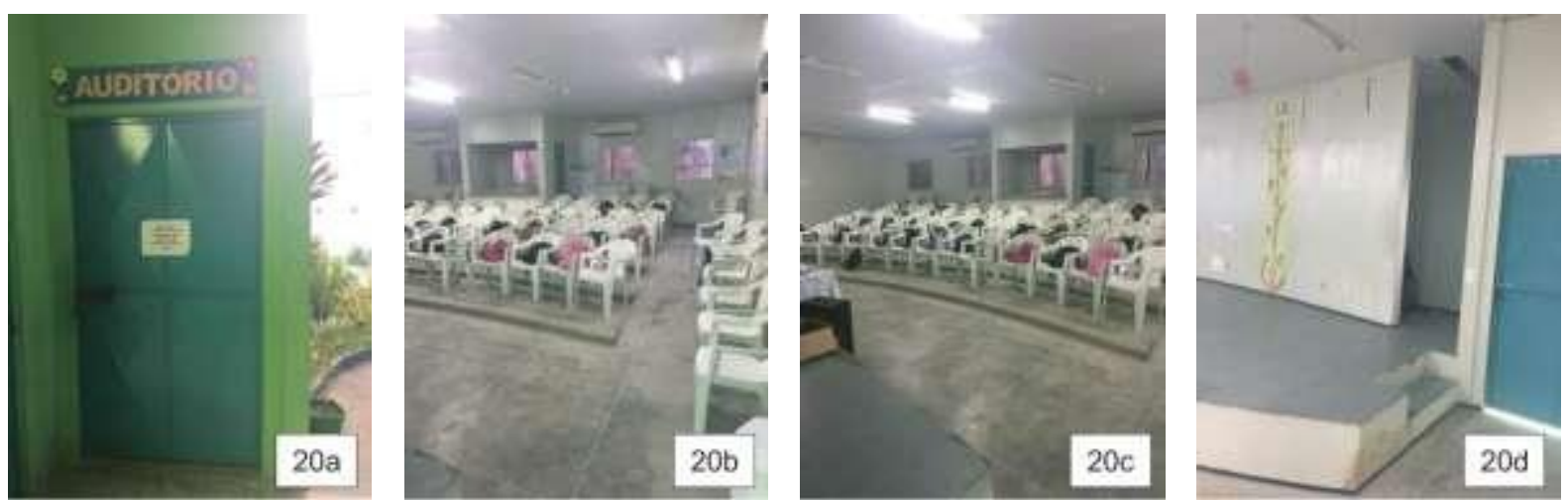

Fonte Figuras 20a, 20b, 20c e 20d: Acervo da Pesquisa (2017).

\subsection{Salas de Aula}

Já os ambientes de sala, em sua maioria, possuem características positivas quanto à acessibilidade física, normalmente com vão de porta adequado, com contraste visual entre piso e parede, altura correta de quadro verde (lousa) e com disponibilidade de mesas com altura adequada ao uso por pessoas em cadeira de rodas (Figura 21a). O mesmo problema quanto à maçaneta é encontrado aqui, em que em muitos casos não há ou é usada a maçaneta tipo bola (Figura 21a). Verificou-se também que não raramente, a comunicação visual, quando existente, também se encontra em altura acima da recomendada (Figuras 21c e 21d). 


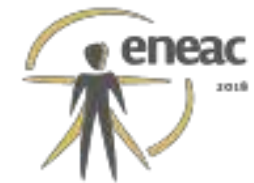

Figura 21 - Salas de aula.
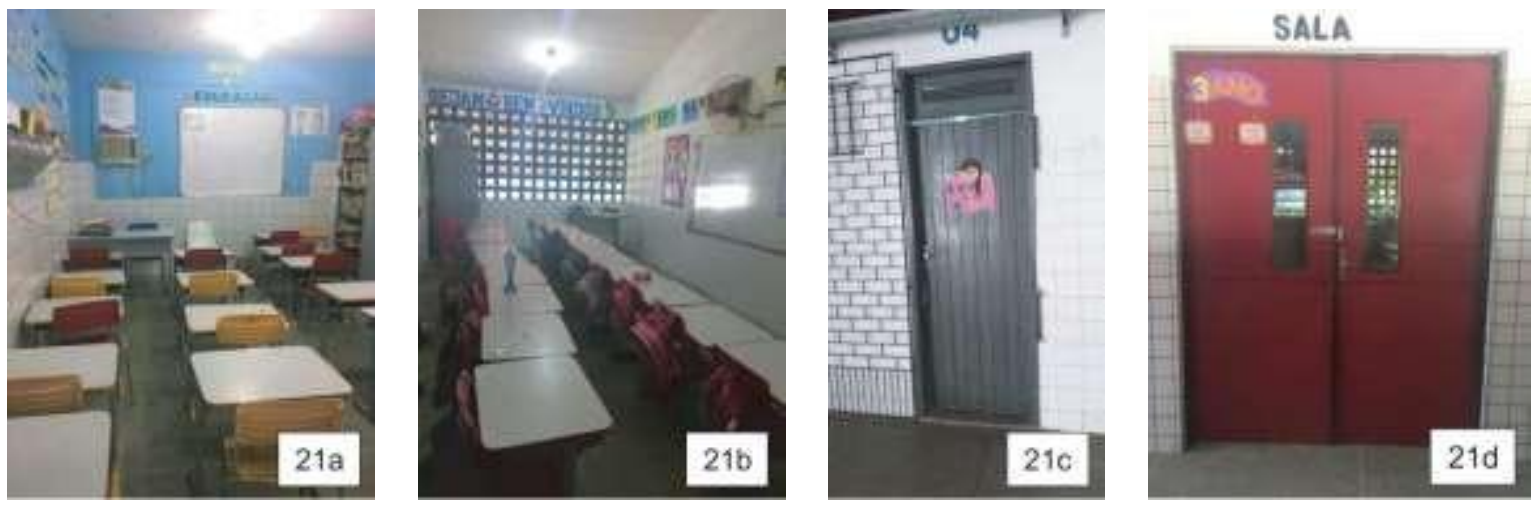

Fonte Figuras 21a, 21b, 21c e 21d: Acervo da Pesquisa (2017).

\subsection{Banheiros}

Quanto aos banheiros de alunos, em sua maioria, há acessibilidade apenas na entrada, com vão de porta adequado, mas existem poucos banheiros com cabines acessíveis (Figura 22). As pias, em muitos casos, possuem altura em discordância com a norma, com torneiras do tipo rosca, que dificultam o uso com pessoas com mobilidade reduzida (Figura 23).

É possível verificar que, na grande maioria dos casos, há um espaço suficiente para um banheiro acessível, porém não há auxílio técnico para correta instalação acarretando um banheiro inacessível (Figura 22). Esse acaba sendo um espaço com potencial, mas mal aproveitado.

\section{Figura 22 - Banheiro.}

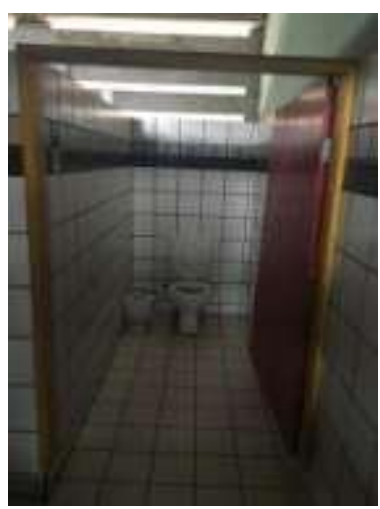

Fonte: Acervo da Pesquisa (2017).
Figura 23 - Banheiro.
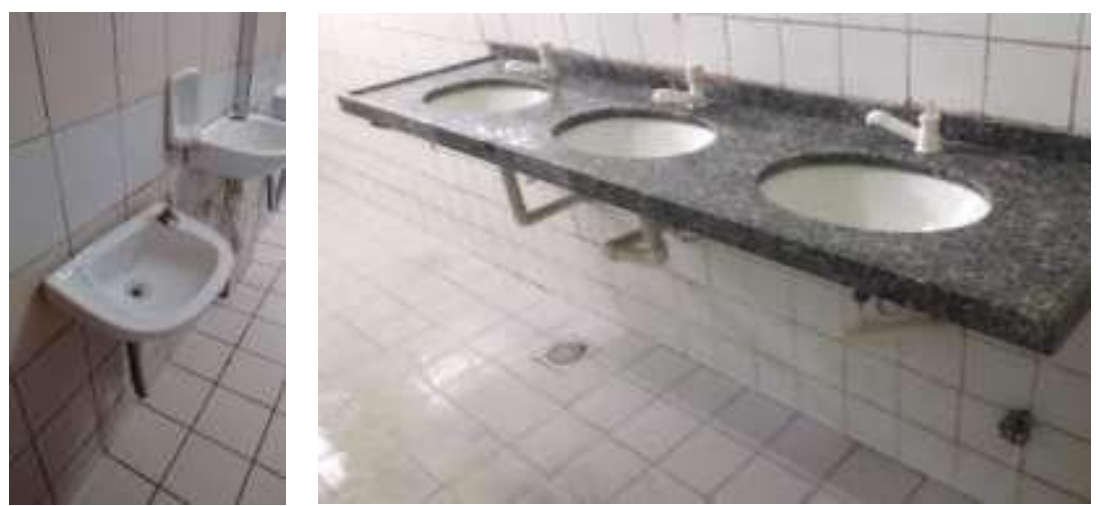

Fonte: Acervo da Pesquisa (2017).

Figura 24 - Banheiro acessível em desacordo com a NBR 9050/2015.
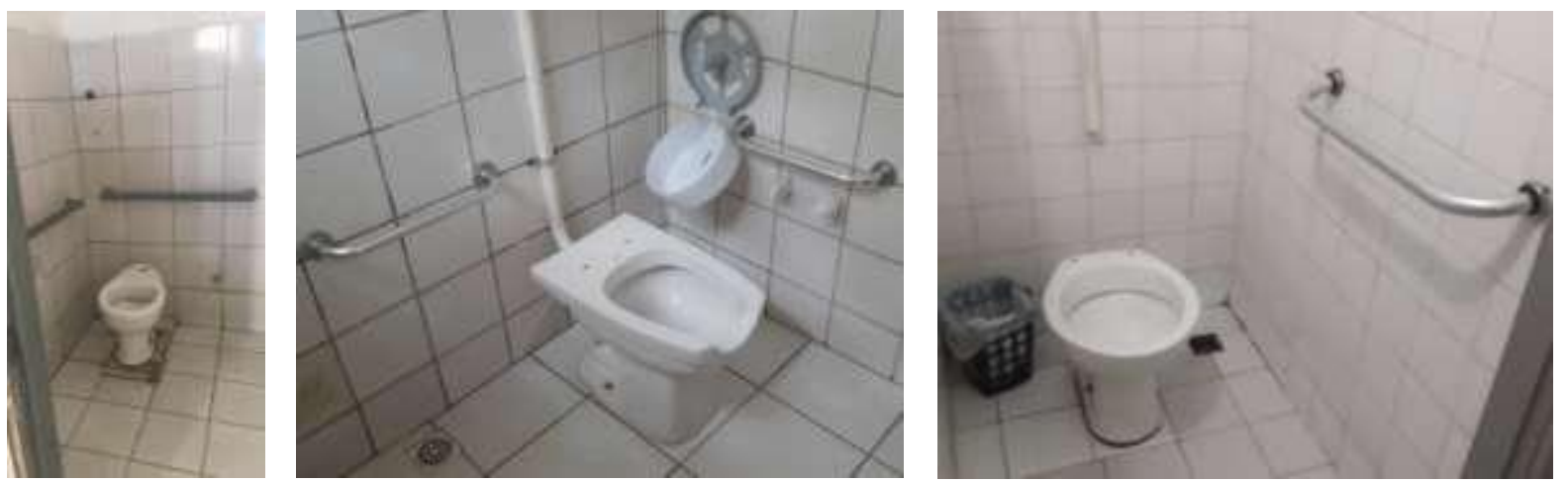

Fonte: Acervo da Pesquisa (2017). 


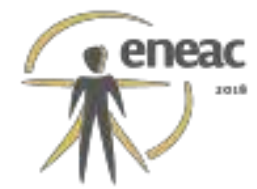

Em alguns casos, há ainda a tentativa de uma cabine acessível, mas com muitas discordâncias quanto à norma, com alturas de barras erradas, barras localizadas em posições não adequadas (Figura 24). Normalmente não há comunicação visual para o banheiro acessível.

Já os banheiros para professores e funcionários não demonstram preocupação com a acessibilidade. Em quase todas as escolas visitadas, não há banheiro acessível dedicado somente aos funcionários. É possível encontrar diversas barreiras a partir da porta de acesso, que costuma ser inferior ao mínimo recomendado de $0,80 \mathrm{~m}$; as pias, às vezes, apresentam barreiras impedindo a aproximação por cadeiras de rodas (vide Figura 25).

Figura 25 - Banheiro de funcionários.
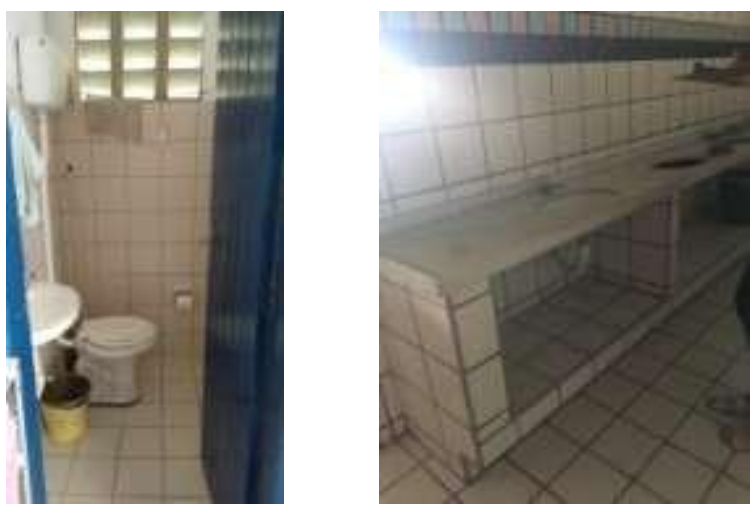

Fonte: Acervo da Pesquisa (2017).

\subsection{Sala de Atendimento Educacional Especializado - AEE}

Essa sala possui como premissa básica oferecer atividades e recursos pedagógicos acessíveis a alunos com necessidades especiais. Visto isso, este deveria ser um ambiente completamente acessível, que garantisse pleno acesso e uso por parte desses alunos. De forma geral, o acesso possui vão de porta adequado, porém comumente com desníveis (Figura 26a); área disponível condizente com o uso, porém ainda com algumas barreiras físicas e em alguns casos sem contraste visual no ambiente (Figuras $26 b$ e 26c). O uso de EVA é bastante comum (Figuras $26 \mathrm{~b}$ e $26 \mathrm{c}$ ), visto que por normalmente as atividades dessa sala acontecem com os alunos sentados no chão, e os professores entendem que esse material é adequado, por ser mais confortável. Porém, o uso desse material dificulta a locomoção da cadeira de rodas e deve ser evitado quando se utiliza a cadeira de rodas.

Figura 26 - Sala de AEE.
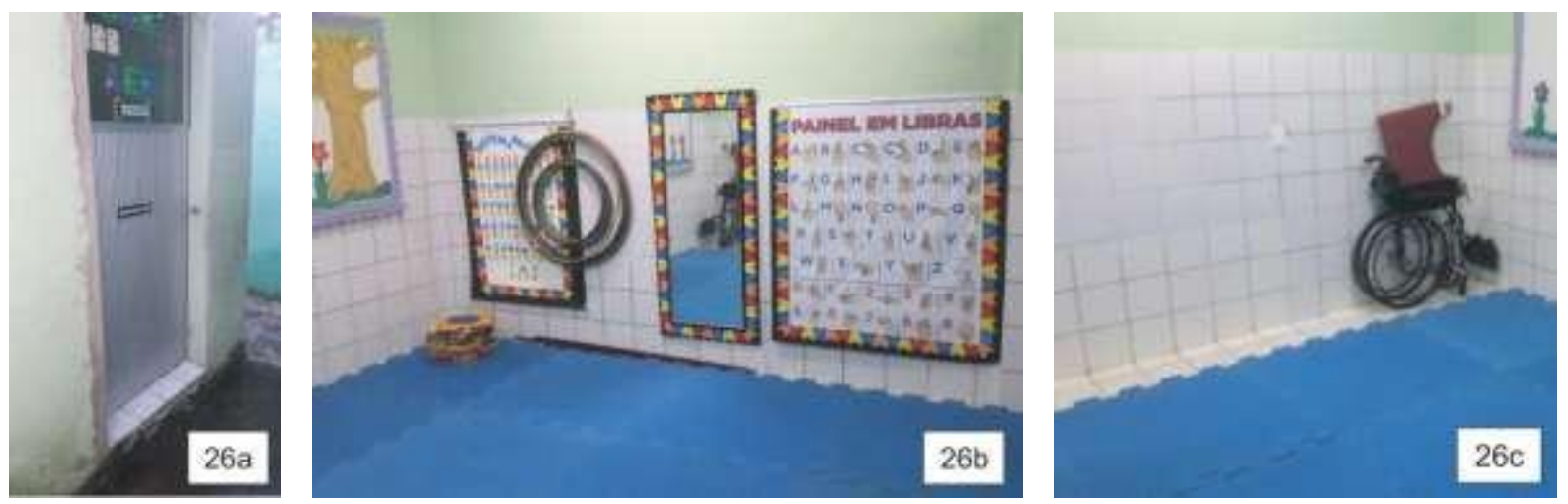

Fonte: Acervo da Pesquisa (2017). 


\subsection{Quadra Poliesportiva}

$\mathrm{Na}$ maioria das escolas, por estar localizado mais afastado da edificação em si, o acesso à quadra acaba se tornando pouco acessível, em alguns casos com rampas e/ou com piso desgastado (Figura 27a). Além disso, na maioria dos casos, a quadra não oferece espaço de permanência para pessoas em cadeira de rodas (Figuras 27b e 27c) e não possui alambrado adequado de proteção às arquibancadas (Figura 27a e 27b). É preciso prever esses espaços para assegurar a permanência e o completo acesso. $O$ alambrado, por sua vez, assegura a integridade física dos alunos de forma geral.

Figura 27 - Quadra Poliesportiva.
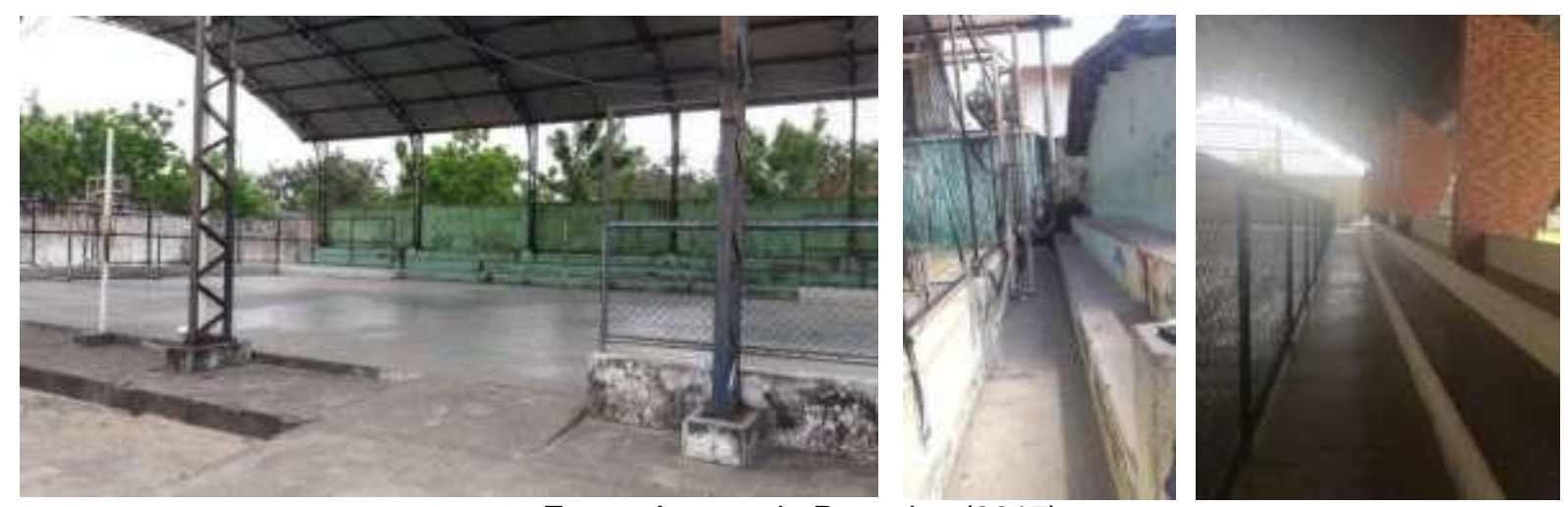

Fonte: Acervo da Pesquisa (2017).

\section{CONSIDERAÇÕES FINAIS}

Há uma grande deficiência quanto à acessibilidade em geral nas escolas visitadas. Seja em relação aos desníveis que a maioria apresenta, seja nos ambientes administrativos, que apresentam grande carência nos critérios de acessibilidade. No caso dos banheiros de alunos e refeitórios, nota-se uma vontade de fazer algo, uma preocupação com o tema, porém falta assessoria técnica para a sua correta concepção e execução, garantindo então o pleno acesso.

É perceptível que há preocupação quanto à acessibilidade nos ambientes gerais das escolas, principalmente nos ambientes mais utilizados pelos alunos, sendo perceptível nas salas de aula. Ainda assim, há questões importantes que precisam de maior atenção e embasamento técnico, mesmo nesses ambientes em que a acessibilidade já deveria ocorrer de forma correta, visando o acolhimento de todo e qualquer aluno em suas dependências.

Os resultados desta pesquisa, em formato de relatório técnico, fornecem subsídios e recomendações acerca da acessibilidade físicas das escolas públicas de Fortaleza. É facilmente perceptível que estes resultados demonstram o quanto o ambiente escolar público em Fortaleza ainda não garante plena acessibilidade física, e demanda, portanto, que profissionais com conhecimento das normas relativas ao tema sejam consultados para possíveis reformas. E tão importante, ou mais, é a presença desse profissional capacitado nos futuros projetos de escolas públicas.

Esses resultados são entregues ao Ministério Público do Ceará, em formato de relatório técnico, e a partir desses resultados, acontecem reuniões a fim de que esses dados possam vir a ser usados em prol de melhorias. Espera-se que, diante da notória importância que possui, a acessibilidade espacial possa deixar de ser apenas uma intenção existente nos edifícios públicos escolares e passe a ser uma premissa básica de projeto. 


\section{REFERÊNCIAS BIBLIOGRÁFICAS}

ASSOCIAÇÃO BRASILEIRA DE NORMAS TÉCNICAS. NBR 9050: Acessibilidade a edificações, mobiliário, espaços e equipamentos urbanos. Rio de Janeiro, 2015.

BRASIL. Decreto № 5.296, de 2 de dezembro de 2004, que regulamenta as Leis $n^{\circ} \mathrm{s} 10.048$, de 8 de novembro de 2000, que dá prioridade de atendimento às pessoas que especifica, e 10.098, de 19 de dezembro de 2000, que estabelece normas gerais e critérios básicos para a promoção da acessibilidade das pessoas com deficiência ou com mobilidade reduzida, e dá outras providências.

CAMBIAGHI, Silvana Serafino. Desenho Universal: métodos e técnicas de ensino na graduação de arquitetos e urbanistas. (Dissertação - Mestrado em Estruturas Ambientais Urbanas FAUUSP). São Paulo, 2004.

SANTIAGO, Z. M. P. Acessibilidade física no ambiente construído: o caso das escolas municipais de ensino fundamental de Fortaleza-CE (1990 - 2003). Dissertação de Mestrado. FAUUSP, São Paulo, 2005.

ORNSTEIN, Sheila; ROMÉRO, Marcelo. Avaliação Pós-Ocupação (APO) do ambiente construído. São Paulo: Studio Nobel; Editora da Universidade de São Paulo, 1992.

PREISER, Wolfgang F.E. Post-occupancy evaluation. New York: Van Nostrand Reinhold, 1988. 